\section{ALL WILD LIFE IS HERE}

The Penguin Dictionary of British Natural History By Richard Fitter. Assisted by Maisie Fitter. Pp. 348. (Harmondsworth, Middx. : Penguin Books, Ltd., 1967.) 8s. $6 d$.

THE naturalist in the field is the latest person to benefit from the valuable series of Penguin dictionaries.

In this case, as befits a dictionary of natural history, the greatest number of entries are names of animals and plants. There are descriptions of birds, butterflies, fishes, insects, reptiles, flowers, fungi and trees, entered under their common names. The binomial names of each species, and their vernacular equivalents, are given in an index of species at the end of the book. All phyla and classes are also entered and each animal or plant can be fully classified through two names which are given after each species entry. The student and amateur naturalist now have a readily available way of linking common names to scientific names, which they must find useful. The important task of identifying animals and plants is not, of course, aided at all, and the identification manuals are certainly not made redundant.

Although this is not a dictionary which is specifically concerned with biology, terms which are in use with the field naturalist are included. For example, mimicry, polymorphism, gene, polyploid, hetero- and homozygote are explained for the amateur-a mutation is described as "A change in one of the genes of a chromosome". Mitosis, meiosis and other technicalities are not here. Various other ecological and ethological terms are included when they are relevant to natural history. There are also entries dealing with physical, meteorological, geographical and geological phenomena--there is a geological time scale which should be very useful to all those who can never remember the order and dates of the various periods.

A paperback probably will not stand up well to life in the field, and so this dictionary has to be recommended as a useful addition to the naturalist's bookshelf.

\section{MaRY LindLey}

\section{MODERN ALGEBRA}

\section{Lectures on Modern Algebra}

By P. Dubreil and M. L. Dubreil-Jacotin. Translated by $\mathbf{A}$. Geddes. (University Mathematical Monographs.) Pp. xii +364 . (Edinburgh and London: Oliver and Boyd, Ltd., 1967.) 105s. net.

THFre are many textbooks on modern algebra. Most introduce the student to the usual structures, including groups, rings, fields, vector spaces and perhaps lattices. This book does this too; but there is a difference, in that there is a strong motivation coming from a hidden source. What is this source? It is the body of algebraic knowledge now referred to as commutative algebra. Even this subject is of recent origin, arising, as it does, from algebraic deficiencies of a fundamental character thrown up by a study of algebraic geometry. It is rather surprising then that nowhere in the book is there any mention of algebraic geometry or of commutative algebra. The nearest the author comes to this is on page 142 where, in an example, it is remarked that the set of polynomials (of a polynomial ring) "which vanish at a given point, or at $k$ given points, or on a given set of curves and points, is an ideal". It is a pity that the contact with algebraic geometry is so marginal.

In spite of what has been said about motivation there is no doubt that the book is an excellent text for the student of modern algebra. It carefully develops the theory from the most elementary concepts, and, while it oontains no exercises, there is a good sprinkling of illustrative examples. A particularly pleasing feature is the inclusion of a chapter on lattice theory (largely in order to discuss the lattice of ideals of a commutative ring) and a chapter on noetherian rings. The last chapter, essentially on field extensions, contains sections on integral dependence and on the famous Nullstellensatz of Hilbert. These remarks on content serve to indicate how closely the material in the book is oriented towards commutative algebra. The book is a translation of the second edition of Leçons d'Algèbre Moderne, and it is number six in the series of "University Mathematical Monographs". The usual high standard of printing by Oliver and Boyd is everywhere evident.

L. S. GODdARD

\section{BOOK OF SPECTRA}

\section{Atlas of Electron Spin Resonance Spectra}

By B. J. H. Bielski and J. M. Gebicki. Pp. xiii +665 . (New York: Academic Press, Inc.; London: Academic Press, Inc. (London), Ltd., 1967.) $220 s$.

THE word "Atlas" is a bit misleading. This mammoth book, which must have taken a great deal of time and effort to compile, is more like a rambler's guide bookone of those interesting and often delightful works that take the reader down many quaint by-ways, thereby avoiding terrain that has become commonplace.

This book will appeal to the expert, both as a source of information and as something to browse in. Basically, it consists of well reproduced esr spectra together with the appropriate references, the source of the paramagnetic material, and its nature. The field of organic radicals in fluid solution is quite well covered, as is that of radicals in systems of biological interest. The field of organic or inorganic radicals in solids is very sparse and the huge fields of colour centres and transition metal complexes are almost entirely omitted. For example, there is just one lonely reference to $\mathbf{F}$-centres, and I cannot help feeling that this should have been replaced by a clear statement that F-centres were not covered, together with a list of references to appropriate reviews on the subject.

More serious omissions arise in another way. In recent years many authors to save space, particularly in cases where good spectra have been obtained the interpretation of which is clear, have published the derived parameters rather than the actual spectrum. No mention of these studies is made and hence this atlas cannot in any sense be taken as being comprehensive even in the limited areas covered.

The work is completely uncritical and therefore often very misleading, for many incorrect or improbable "identifications" are quoted. Some of these relate to work of at least ten years ago, the authors of which would surely no longer hold to their original assignments.

A remarkable number of spectra are listed as "unpublished results", and in some cases one realizes why. However, because often no interpretation is then offered, the reader can amuse himself by testing his own interpretative skill.

The order of presentation is often most puzzling, and anyone who decides to read consecutively will be astonished at its vagaries. More serious, however, are the many errors.

The symbol $a_{\mathrm{H}}$ is a popular one for these authors and is applied in many cases to describe the hyperfine parameters for a large number of nuclei, not just hydrogen. Certain peroxy-radicals formed in the reaction of hydrogen peroxide with titanous salts are incorrectly described as the hydroxyl radical. 'The $N$-methyl pyridinium ion is said to be the source of an interesting esr spectrum and is described as the methylviologen cation radical.

The reader may be taken aback by the large number of spectra assigned to nitrogen dioxide. In fact, only two of these are anything to do with $\mathrm{NO}_{2}$, the others being, in my opinion, various radicals formed by reaction 